\title{
Suitability of sugar, amino acid, and inorganic ion compositions to distinguish fir and spruce honey
}

\author{
Basel Shaaban ${ }^{1} \cdot$ Victoria Seeburger $^{2} \cdot$ Annette Schroeder $^{2} \cdot$ Gertrud Lohaus $^{1}$ (I)
}

Received: 30 September 2020 / Revised: 9 December 2020 / Accepted: 12 December 2020 / Published online: 9 February 2021

(c) The Author(s) 2021

\begin{abstract}
Honeydew honey is produced by bees from excretions of plant-feeding insects, such as aphids and scale insects. Honeydew on conifers, like fir (Abies alba) or spruce (Picea abies), is produced by different species of the genera Cinara and Physokermes. This means that honeydew honey can stem from different botanical as well as zoological origins, but so far it is not possible to clearly distinguish the different types of honeys. In the attempt to identify distinguishing markers, 19 sugars, 25 amino acids and 9 inorganic ions were quantified in three groups of honeydew honey (fir/Cinara, spruce/Cinara and spruce/Physokermes) with 20 honey samples each. It could be demonstrated that the contents of isomaltose, raffinose, erlose, two undefined oligosaccharides, several amino acids, sulfate, and phosphate differed significantly between the three groups of honey. Furthermore, multivariate analyses resulted in a separation of spruce/Physokermes honey from spruce- or fir/Cinara honey due to its higher contents of phosphate, sulfate, erlose and two undefined oligosaccharides. Moreover, the amino acid composition and the isomaltose as well as the raffinose contents proved useful in the distinction between fir/Cinara and spruce/Cinara honey. In sum, the contents of sugars, amino acids, and inorganic ions in German fir and spruce honeys provide useful information about the botanical and zoological origin of honeydew honeys.
\end{abstract}

Keywords Honeydew honey $\cdot$ Fir honey $\cdot$ Spruce honey $\cdot$ Sugars $\cdot$ Free amino acids $\cdot$ Inorganic ions

\section{Introduction}

Honeydew honey is a natural sweet substance produced by Apis mellifera from secretions of living parts of plants or from excretions of plant-feeding insects [1]. Different insects of the order Hemiptera, such as aphids and scale insects, feed on phloem sap of their host trees and utilize the contained amino acids as nutrients [2]. They excrete sugars that are not used for nutrition in the form of honeydew. The composition of honeydew varies between different insect species and it is also influenced by the host plant species and different environmental conditions [3-5]. The genera Cinara (Lachnidae) or Physokermes (Coccidae) feeding on conifers like spruce, fir, or pine are known to produce large amounts of honeydew. There are also species of other hemipteran

Gertrud Lohaus

lohaus@uni-wuppertal.de

1 Molecular Plant Science/Plant Biochemistry, University of Wuppertal, Wuppertal, Germany

2 Apicultural State Institute, University of Hohenheim, Stuttgart, Germany feeding on deciduous trees, like oak, chestnut or lime trees that produce honeydew [6]. Honey bees (Apis mellifera) collect honeydew for nutrition and produce a special kind of honey, known as honeydew-, forest-, fir- or spruce-honey. Therefore, the components of honeydew honey originate from the plant (botanical origin), from the honeydew producing insect (zoological origin), or they are added by the honey bees in the process of honey-production (additional zoological origin).

Honey contains mainly sugars $(70-80 \%, w / w)$ and water (10-20\%,w/w), but also a large number of minor components, such as amino acids, organic acids, minerals, phenolic compounds, enzymes, or proteins [1]. The chemical composition and the biochemical and physiochemical parameters of honeydew honey differ from that of flower honey (based on nectar) in parameters such as electrical conductivity, $\mathrm{pH}$, sugar profile, or mineral content $[7,8]$. The European legislation [1] states that flower honey (with exceptions) must have electrical conductivity values $\leq 0.8 \mathrm{mS} \mathrm{cm}^{-1}$, whereas honeydew honeys must have electrical conductivity values $\geq 0.8 \mathrm{mS} \mathrm{cm}^{-1}$. The sugar profile is one of the main parameters for the quality control of honey, and it proofs that 
honeydew honey contains less monosaccharides and more di- and oligosaccharides than flower honey [9-12]. However, few studies on the carbohydrate compositions of different honeydew-honey types have been carried out so far [8]. The total amino acid content in honey is about $0.3-2.0 \mathrm{~g} \mathrm{~kg}^{-1}$ with proline being the dominating one $[13,14]$. The amino acid composition in honeys have been used to characterize their geographic or botanical origin, but without highly conclusive results $[13,14]$. The total mineral content in flower honey is generally lower than in honeydew honey (about $0.1-0.2 \%$ and $1 \%$ respectively) due to the higher amounts of $\mathrm{K}$ and $\mathrm{P}$ [15]. The mineral content was also used to determine the honey's botanical origin [16-18].

Authenticity of honeys, including honeydew honey, has become a major subject of investigation at an international level $[8,12,19]$. Honeydew honey is labelled on the basis of sensory judgements and electrical conductivity values, but there is no internationally accepted quality criterion for different types of honeydew honeys [7, 8]. As for flower honey, pollen analysis (melissopalynology) is used to identify the botanical origin; this method, however, is not useful for honeydew honey [8]. There are several studies dealing with the characterization of honeydew honey in general, but so far, only a small number of studies attempted to identify the botanical origin of honeydew honeys $[8,18]$.

Because of its strong malty-aromatic taste, honeydew honey is very popular and achieves a high market value [8]. Some compounds have been suggested to be specific botanical markers for several different honeydew honeys, such as quercitol for oak honey, 1-chloro-octane and tridecane for pine honey or protocatechuic acid for fir honey [20-25]. However, it was shown that the content of protochatechuic acid was similar in the honeys of different conifers, and protochatechuic acid can therefore only be used to differentiate between flower and honeydew honey [26, 27]. Additionally, there are no specific markers to differentiate between honeydew honey from spruce and fir and, to the best of our knowledge, there are no studies that investigated the characterization of the botanical as well as zoological origin of these kinds of honeys.

Honey is frequently subjected to adulteration or to mislabeling of the origin. Therefore, it is necessary to determine reliable parameters to verify the botanical and zoological authentication of honeydew honey [8, 12]. In Germany, the main proportion of coniferous honeydew honey originates from spruce or fir [6]. The main objective of this study, therefore, was to investigate whether it is possible to differentiate between honeydew honey of fir (Abies alba Mill.) and spruce [Picea abies (L.) H. Kast.]. For that purpose, the contents of sugars, amino acids, and inorganic ions in honeydew honey in relation to the host tree species, either fir or spruce (botanical origin), as well as the hemipteran species which produced the honeydew, either Cinara or
Physokermes (zoological origin), were analyzed. The honeydew honeys' contents of sugar, amino acid, and inorganic ion were conflated with multivariate analyses.

\section{Materials and methods}

\section{Sample collection}

Honeydew honeys of silver fir (Abies alba Mill.) and spruce [Picea abies (L.) H. Kast.] were obtained from selected beekeepers by the Apicultural State Institute, University of Hohenheim (Stuttgart, Germany). All honeys were collected from several parts of Baden-Württemberg (Germany) between 2017 and 2019. The samples were marked by beekeepers and classified by the botanical and zoological origin, indicated by the location where the beehives were positioned. The honeydew producers were Cinara spec. on fir and Cinara spec. or Physokermes spec. on spruce, which has been verified by the Apicultural State Institute, University of Hohenheim (Stuttgart, Germany).

Furthermore, human sensorial analyses of the aromas were carried out by the Apicultural State Institute, University of Hohenheim (Stuttgart, Germany) to confirm the honeydew nature of all honey samples. For fir/Cinara honeys, there were warm and caramelized aromas, reminding of dates, toffee, fresh butter, and vanilla with a subtle note of lemon; for spruce/Cinara honeys, there were spicy, resinous and a little balsamic aroma; and for fir/Physokermes honeys, the aromas were woody like leafy wood dust.

Twenty samples of each honey type (fir/Cinara, spruce/Cinara, and spruce/Physokermes) were analyzed. Samples were stored at about $18-20{ }^{\circ} \mathrm{C}$ and dry and dark conditions. All honeydew honey samples had electrical conductivity values $\geq 0.8 \mathrm{mS} \mathrm{cm} \mathrm{cm}^{-1}$. The average water content was $16.3 \pm 0.8 \%$ for fir/Cinara, $16.0 \pm 1.6 \%$ for spruce/Cinara, and $15.7 \pm 1.8 \%$ for spruce/Physokermes honeydew honey; no significant differences between the three honey groups were found.

\section{Honey preparation for analyses}

$1 \mathrm{~g}$ of honey was dissolved in $40 \mathrm{~mL}$ ultrapure water. The solution was centrifuged for $10 \mathrm{~min}$ at $5,000 \mathrm{rpm}$ to separate pollen and other material. The solutions were stored at $-80{ }^{\circ} \mathrm{C}$ until analyses. All honey samples were analyzed in the year of collection.

\section{Analyses of sugars}

High performance anion-exchange chromatography with pulsed amperometric detection (HPAEC-PAD) was used for the analysis of mono-, di-, and oligosaccharides in honey 
according to Shaaban et al. [5]. Honey samples were diluted with ultrapure water so that they provide signals within the linear range of the detector response, for each sample two different dilutions were analyzed (1:1000 for glucose and fructose, and 1:40 for di- and oligosaccharides). Sugars were separated with an anion-exchange column (CarbopacTM PA10 $4 \mathrm{~mm} \times 250 \mathrm{~mm}$; Dionex corp, Sunnyvale, CA, US), eluted isocratically with $80 \mathrm{mM}$ sodium hydroxide, and detected with a pulse amperometric detector (ESA Model 5200, Coulochem II, Bedford, MA, US). Pulse setting was at 50,700 , and $-800 \mathrm{mV}$ for 500,540 , and $540 \mathrm{~ms}$, respectively. Standards for glucose, fructose, sucrose, trehalose, turanose, kojibiose, gentiobiose, maltose, isomaltose, maltulose, isomaltulose, melezitose, erlose, raffinose, 1-kestose, isomaltotriose, maltotriose, nigrose, stachyose were measured in parallel $(0-250 \mu \mathrm{mol} / \mathrm{L})$ and for each sugar, a calibration curve was created. Sugars were quantified by comparing their chromatographic peak area to that of the standard calibration curve. Furthermore, the obtained results were checked regularly with the standard addition method. Long-chain oligosaccharides [degree of polymerization (DP) $\geq 5$ ] were analyzed with the same system, with the difference that the column was eluted isocratically with $200 \mathrm{mM} \mathrm{NaOH}$ instead of $80 \mathrm{mM} \mathrm{NaOH}$.

\section{Limit of detection and limit of quantification of the identified sugars}

The calibration curves were prepared in triplicates $(n=3)$ at five different dilutions $(0-250 \mu \mathrm{mol} / \mathrm{L})$. The determination coefficients for the calibration curves of the different sugars were each $R^{2}>0.99$. Limit of detection (LOD) and limit of quantification (LOQ) values were determined using regression parameters from the calibration curve $\left(3.3 \mathrm{~S}_{\mathrm{y} / \mathrm{x}} / a\right.$ and $10 \mathrm{~S}_{\mathrm{y} / \mathrm{x}} / a$, respectively; where $\mathrm{S}_{\mathrm{y} / \mathrm{x}}$ is the standard deviation of the residues and $a$ is the slope) [19]. With the HPAECPAD system described above, the aforementioned LOD was the best for glucose $(0.6 \mu \mathrm{mol} / \mathrm{L})$ and the worst for erlose $(1,0 \mu \mathrm{mol} / \mathrm{L})$ and the corresponding LOQ were $1.8 \mu \mathrm{mol} / \mathrm{L}$ (glucose) and $3.0 \mu \mathrm{mol} / \mathrm{L}$ (erlose). The values for the other sugars were distributed between these two limits.

\section{Analyses of amino acids}

The analysis of free amino acids by HPLC was performed according to Göttlinger et al. [28]. Amino acids with a primary amino group were processed by precolumn derivatization with o-phtaldialdehyde, amino acids with a secondary amino group (e.g., proline) with fluorenylmethyloxycarbonyl. The separation of amino acids was performed on a reversed-phase column (LiChroCart 125-4, Superphere 100 RP-18 endcapped; Merck, Darmstadt, Germany) with an acetonitrile gradient in $18 \mathrm{mM}$ potassium phosphate, $\mathrm{pH}$
7.1. The derivatives were detected by fluorescence using wavelengths of excitation and emission at 330 and $405 \mathrm{~nm}$ (o-phtaldialdehyde) or 265 and $305 \mathrm{~nm}$ (fluorenylmethyloxycarbonyl). Amino acid standards (Sigma-Aldrich, Germany) were measured in parallel $(0-20 \mu \mathrm{M})$ and for each amino acid a calibration curve was created.

\section{Limit of detection and limit of quantification of the identified amino acids}

The calibration curves were prepared in triplicates $(n=3)$ at four different dilutions $(0-20 \mu \mathrm{mol} / \mathrm{L})$. The determination coefficients for the calibration curves of the different amino acids were between $R^{2}=0.99-0.93$. Limit of detection (LOD) and limit of quantification (LOQ) values were determined using regression parameters from the calibration curve (3.3 $\mathrm{S}_{\mathrm{y} / \mathrm{x}} / a$ and $10 \mathrm{~S}_{\mathrm{y} / \mathrm{x}} / a$, respectively; where $\mathrm{S}_{\mathrm{y} / \mathrm{x}}$ is the standard deviation of the residues and $a$ is the slope) [19]. With the HPLC system described above, the aforementioned LOD was the best for glutamate $(0.17 \mu \mathrm{mol} / \mathrm{L})$ and the worst for tryptophane $(0.30 \mu \mathrm{mol} / \mathrm{L})$ and the corresponding LOQ were $0.51 \mu \mathrm{mol} / \mathrm{L}$ (glutamate) and $0.90 \mu \mathrm{mol} / \mathrm{L}$ (tryptophane). The values for the other amino acids were distributed between these two limits.

\section{Analyses of inorganic ions}

Anions $\left(\mathrm{Cl}^{-}, \mathrm{PO}_{4}{ }^{3-}, \mathrm{SO}_{4}{ }^{2-}, \mathrm{NO}_{3}{ }^{-}\right)$and cations $\left(\mathrm{K}^{+}, \mathrm{Na}^{+}\right.$, $\mathrm{Mg}^{2+}, \mathrm{Ca}^{2+}, \mathrm{NH}_{4}^{+}$) were analyzed separately by ion chromatography connected with a conductivity detector (DX 500, Dionex, Idstein, Germany) according to Göttlinger et al. [28]. Anions were separated using an IonPac anion exchange column (AS4, 4× $200 \mathrm{~mm}$, Dionex Corp, Sunnyvale, CA, USA) and the ions were eluted with $1.8 \mathrm{mM} \mathrm{Na}_{2} \mathrm{CO}_{3}$ and $1.7 \mathrm{mM} \mathrm{NaHCO}$. Cations were separated using an IonPac cation exchange column (CS12A, $4 \times 200 \mathrm{~mm}$, Dionex Corp, Sunnyvale CA, USA) and the ions were eluted with $15 \mathrm{mM}$ $\mathrm{H}_{2} \mathrm{SO}_{4}$. Inorganic ion standards (Sigma-Aldrich, Germany) were measured in parallel $(0-750 \mu \mathrm{M})$ and for each anion or cation a calibration curve was created.

\section{Statistical analyses}

Sugar, amino acid, or ion contents in honeydew honey are shown as means $( \pm \mathrm{SD})$. The means of each of the sugars, amino acids, or ions in the three groups of honey (fir/Cinara, spruce/Cinara, and spruce/Physokermes) were compared separately to check for significant differences. Skewness and kurtosis were calculated to capture the distribution of the dataset; normal distribution was assumed if skewness values were less than two and kurtosis values were less than seven [29]. Moreover, Levene's tests were applied to test for homogeneity of variances for the data of each metabolite 
or ion. When data conformed to the normality assumption but failed on homogeneity of variances, analysis of variance was performed using the Welch's test followed by post-hoc test (Games-Howell test). For the cases where both normality and homogeneity assumptions were confirmed, one-way ANOVA was performed. Subsequently, post-hoc tests (Tukey's HSD) were carried out ( $p$ value $<0.05$ ).

In order to investigate whether the differences in sugar, amino acid, and ion contents could be explained by the zoological and/or the botanical origin of the honeydew honey samples, a Powered Partial Least Squares-Discriminant Analysis (PPLS-DE) was performed. All values for sugars, amino acids, and ions were taken for the PPLS-DE and values were then autoscaled. For PPLS-DA, the performance of the model must be assessed before any interpretation of score plots is possible. Therefore, the number of misclassifications (or error rate), i.e., the number of samples that do not belong to the group predicted by the model, was calculated (outer loop: sevenfold CV, inner loop: sixfold CV). Then, a permutation test based on the classification error rate was used to determine the statistical significance of the differences between groups. Lastly, pairwise comparisons of the zoological origins were performed. PPLS-DE analysis was performed using the 'pls' and 'RVAideMomoire' packages with the cppls, MVA.cmv, MVA.test, pairwise.factorfit and MVA.plot routines [30-35].

All statistical analyses were performed using $\mathrm{R}$ (version 3.5.1, www.r-project.org) and SPSS (version 24.0, IBM, Cooperation).

\section{Results}

\section{Sugars in honeydew honey}

Honeydew honey samples were analyzed for sugars, amino acids and ions. The monosaccharides fructose and glucose were the dominant sugars in all samples (about $60 \mathrm{~g} / 100 \mathrm{~g}$ honey), and the fructose content was higher than that of glucose in both fir and spruce honey (Table 1). No significant differences between the three groups of honey were found. Different disaccharides were detected in all honeydew honey samples, with trehalose and isomaltose showing the highest contents and the isomaltose content was significantly higher in fir honey than in both types of spruce honey. It must be stated, however, that the isomaltose peak was not separated from the maltulose peak. Melezitose and erlose were the dominant trisaccharides. Melezitose was the most abundant trisaccharide in fir/- and spruce/Cinara honey, whereas the erlose content was significantly higher in spruce/Physokermes honey compared to the other honey samples. The raffinose content was significantly higher in fir/Cinara honey than in
Table 1 Sugar contents in three groups of honeydew honey (Abies alba/Cinara spec., Picea abies/Cinara spec., and Picea abies/Physokermes spec.)

\begin{tabular}{|c|c|c|c|}
\hline \multirow[t]{2}{*}{ Sugars $[g / 100 \mathrm{~g}]$} & \multirow{2}{*}{$\begin{array}{l}\text { Abies alba } \\
\text { Cinara sp. }\end{array}$} & \multicolumn{2}{|l|}{ Picea abies } \\
\hline & & Cinara sp. & Physokermes sp. \\
\hline Fructose (fru) & $30.6 \pm 3.1^{\mathrm{a}}$ & $31.0 \pm 2.9^{\mathrm{a}}$ & $29.7 \pm 2.7^{\mathrm{a}}$ \\
\hline Glucose (glu) & $28.5 \pm 2.2^{\mathrm{a}}$ & $27.7 \pm 3.0^{\mathrm{a}}$ & $27.4 \pm 3.2^{\mathrm{a}}$ \\
\hline Trehalose (tre) & $1.9 \pm 0.7^{\mathrm{a}}$ & $1.3 \pm 0.6^{\mathrm{a}}$ & $1.8 \pm 0.7^{\mathrm{a}}$ \\
\hline Isomaltose* (iso) & $2.4 \pm 1.1^{\mathrm{a}}$ & $1.5 \pm 0.7^{b}$ & $1.5 \pm 0.4^{b}$ \\
\hline Maltose (mal) & $1.1 \pm 0.5^{\mathrm{a}}$ & $1.0 \pm 0.7^{\mathrm{a}}$ & $1.3 \pm 0.8^{\mathrm{a}}$ \\
\hline Kojibiose (koj) & $1.3 \pm 0.5^{\mathrm{a}}$ & $1.3 \pm 0.8^{\mathrm{a}}$ & $1.4 \pm 0.7^{\mathrm{a}}$ \\
\hline Turanose** (tur) & $1.5 \pm 0.7^{\mathrm{a}}$ & $1.4 \pm 0.8^{\mathrm{a}}$ & $1.1 \pm 1.1^{\mathrm{a}}$ \\
\hline Sucrose (suc) & $0.9 \pm 0.5^{\mathrm{a}}$ & $0.8 \pm 0.5^{\mathrm{a}}$ & $1.0 \pm 0.6^{\mathrm{a}}$ \\
\hline Melezitose (mel) & $3.0 \pm 1.6^{\mathrm{a}}$ & $4.1 \pm 3.7^{\mathrm{a}}$ & $2.6 \pm 1.8^{\mathrm{a}}$ \\
\hline Erlose (erl) & $1.5 \pm 1.5^{\mathrm{a}}$ & $1.1 \pm 0.9^{a}$ & $3.2 \pm 2.7^{b}$ \\
\hline Raffinose (raf) & $1.9 \pm 1.1^{\mathrm{a}}$ & $0.8 \pm 0.7^{b}$ & $1.1 \pm 0.8^{b}$ \\
\hline $1-K_{e s t o s e} * * *(\mathrm{kes})$ & $0.3 \pm 0.5^{\mathrm{a}}$ & $0.7 \pm 0.5^{\mathrm{a}}$ & $1.1 \pm 1.2^{\mathrm{a}}$ \\
\hline Undef 1 & $0.1 \pm 0.1^{\mathrm{a}}$ & $0.1 \pm 0.1^{\mathrm{a}}$ & $0.1 \pm 0.1^{\mathrm{a}}$ \\
\hline Undef 2 & $0.2 \pm 0.1^{\mathrm{a}}$ & $0.1 \pm 0.1^{\mathrm{a}}$ & $0.2 \pm 0.1^{\mathrm{a}}$ \\
\hline Undef 3 & $0.3 \pm 0.3^{\mathrm{a}}$ & $0.4 \pm 0.7^{\mathrm{a}}$ & $0.2 \pm 0.3^{\mathrm{a}}$ \\
\hline Undef 4 & $0.9 \pm 0.6^{a}$ & $0.7 \pm 0.5^{a}$ & $1.5 \pm 0.8^{b}$ \\
\hline Undef 5 & $0.1 \pm 0.1^{\mathrm{a}}$ & $0.1 \pm 0.1^{\mathrm{a}}$ & $0.1 \pm 0.1^{\mathrm{a}}$ \\
\hline Undef 6 & $0.7 \pm 0.5^{\mathrm{a}}$ & $0.7 \pm 0.7^{\mathrm{a}}$ & $2.1 \pm 1.0^{b}$ \\
\hline Undef 7 & $0.1 \pm 0.2^{\mathrm{a}}$ & $0.1 \pm 0.2^{\mathrm{a}}$ & $0.1 \pm 0.2^{\mathrm{a}}$ \\
\hline
\end{tabular}

All values are means of $n=20$ independent measurements \pm SD

Different letters represent significant differences between the sugars in the tree groups of honeydew honey. Significantly different values were also marked in bold

*Peak of isomaltose was not completely separated from maltulose peak

**Peak of turanose was not completely separated from isomaltulose and gentiobiose peak

***Peak of kestose was not completely separated from nigerose and stachyose peak

Undef 1 and $2=$ undefined monosaccharides

Undef 3, 4, 5, 6, and 7=undefined oligosaccharides

spruce/Cinara or spruce/Physokermes honey. Several further sugars were detected in the honey samples, named as undefined $1-7$. Undefined sugar 4 and 6 are probably oligosaccharides and their contents were significantly higher in spruce/Physokermes honey than in fir/- or spruce/Cinara honey.

\section{Amino acids in honeydew honey}

The total contents of all free amino acids were low in all honey samples (less than $0.1 \mathrm{~g} / 100 \mathrm{~g}$ honey; Table 2). Proline accounted for up to $90 \%$ of the amino acids and with that it was the dominant amino acid in all samples. Its content was significantly higher in Cinara honey than in Physokermes honey. All other proteinogenic as well as 
Table 2 Amino acid contents in three groups of honeydew honey (Abies alba/Cinara spec., Picea abies/Cinara spec., and Picea abies/Physokermes spec.)

\begin{tabular}{|c|c|c|c|}
\hline \multirow[t]{2}{*}{ Amino acids $[\mathrm{mg} / 100 \mathrm{~g}]$} & \multirow{2}{*}{$\begin{array}{l}\text { Abies alba } \\
\text { Cinara sp. }\end{array}$} & \multicolumn{2}{|l|}{ Picea abies } \\
\hline & & Cinara sp. & Physokermes sp. \\
\hline Proline (PRO) & $54.3 \pm 17.5^{\mathrm{a}, \mathrm{b}}$ & $61.7 \pm 33.0^{b}$ & $40.9 \pm 19.6^{a}$ \\
\hline Glutamate (GLU) & $4.6 \pm 4.5^{\mathrm{a}}$ & $8.4 \pm 10.3^{b}$ & $2.4 \pm 2.6^{\mathrm{a}}$ \\
\hline Glutamine (GLN) & $2.6 \pm 1.7^{\mathrm{a}}$ & $6.4 \pm 4.9^{b}$ & $1.9 \pm 2.1^{\mathrm{a}}$ \\
\hline Aspartate (ASP) & $1.7 \pm 1.5^{\mathrm{a}}$ & $4.5 \pm 4.6^{b}$ & $1.6 \pm 2.5^{\mathrm{a}}$ \\
\hline Asparagine(ASN) & $0.7 \pm 0.6^{a}$ & $2.3 \pm 2.7^{b}$ & $0.8 \pm 2.3^{a}$ \\
\hline Glycine (GLY) & $0.3 \pm 0.1^{\mathrm{a}}$ & $0.5 \pm 0.3^{\mathrm{a}}$ & $0.2 \pm 0.1^{\mathrm{a}}$ \\
\hline Serine (SER) & $0.5 \pm 0.3^{\mathrm{a}}$ & $1.0 \pm 0.9^{\mathrm{a}}$ & $0.6 \pm 0.4^{\mathrm{a}}$ \\
\hline Threonine (THR) & $0.2 \pm 0.1^{\mathrm{a}}$ & $1.0 \pm 1.0^{b}$ & $0.3 \pm 0.3^{\mathrm{a}}$ \\
\hline Alanine (ALA) & $0.9 \pm 0.4^{\mathrm{a}}$ & $2.1 \pm 1.4^{b}$ & $1.0 \pm 1.0^{\mathrm{a}}$ \\
\hline Valine (VAL) & $0.5 \pm 0.4^{\mathrm{a}}$ & $1.7 \pm 1.4^{b}$ & $0.6 \pm 0.4^{\mathrm{a}}$ \\
\hline Isoleucine (ILE) & $0.3 \pm 0.3^{a}$ & $1.6 \pm 1.9^{b}$ & $0.6 \pm 0.7^{a}$ \\
\hline Leucine (LEU) & $0.1 \pm 0.2^{\mathrm{a}}$ & $0.5 \pm 0.3^{\mathrm{a}}$ & $0.3 \pm 0.3^{\mathrm{a}}$ \\
\hline Phenylalanine(PHE) & $0.4 \pm 0.2^{\mathrm{a}}$ & $2.4 \pm 1.6^{b}$ & $0.8 \pm 0.7^{\mathrm{a}}$ \\
\hline Tyrosine (TYR) & $0.6 \pm 0.4^{\mathrm{a}}$ & $2.0 \pm 1.4^{b}$ & $1.0 \pm 0.6^{a}$ \\
\hline Tryptophan (TRP) & $0.1 \pm 0.1^{\mathrm{a}}$ & $0.1 \pm 0.3^{\mathrm{a}}$ & $0.1 \pm 0.1^{\mathrm{a}}$ \\
\hline Arginine (ARG) & $0.1 \pm 0.1^{\mathrm{a}}$ & $0.8 \pm 0.5^{b}$ & $0.2 \pm 0.2^{\mathrm{a}}$ \\
\hline Lysine (LYS) & $0.1 \pm 0.1^{a}$ & $1.1 \pm 0.8^{b}$ & $0.3 \pm 0.2^{\mathrm{a}}$ \\
\hline Histidine (HIS) & $0.1 \pm 0.3^{\mathrm{a}}$ & $0.3 \pm 0.5^{\mathrm{a}}$ & $0.3 \pm 0.5^{\mathrm{a}}$ \\
\hline Methionine (MET) & $0.1 \pm 0.1^{\mathrm{a}}$ & $0.1 \pm 0.1^{\mathrm{a}}$ & $0.1 \pm 0.1^{\mathrm{a}}$ \\
\hline B-Alanine (B-ALA) & $0.5 \pm 0.2^{\mathrm{a}}$ & $1.2 \pm 0.6^{b}$ & $0.5 \pm 0.2^{\mathrm{a}}$ \\
\hline$\gamma$-Amino-butyric acid (GABA) & $0.1 \pm 0.1^{\mathrm{a}}$ & $0.6 \pm 0.3^{\mathrm{a}}$ & $0.3 \pm 0.4^{\mathrm{a}}$ \\
\hline Non-proteinogenic amino acids (NP) & $0.4 \pm 0.4^{\mathrm{a}}$ & $1.2 \pm 0.9^{\mathrm{a}}$ & $0.4 \pm 0.3^{\mathrm{a}}$ \\
\hline
\end{tabular}

All values are means of $n=20$ independent measurements \pm SD

Different letters represent significant differences between the sugars in the tree groups of honeydew honey. Significantly different values were also marked in bold

Further non-proteinogenic amino acids: homoserine, phosphoserine, ornithine, and taurine further non-proteinogenic amino acids were also found in the honey samples, but their contents were low. Nevertheless, the contents of glutamate, glutamine, aspartate, asparagine, threonine, alanine, valine, isoleucine, phenylalanine, tyrosine, arginine, lysine, and $\beta$-alanine differed significantly between the three groups of honey. The contents of these amino acids were higher in spruce/Cinara honey than in fir/Cinara and spruce/Physokermes honey.

\section{Inorganic ions in honeydew honey}

Honeydew honey samples contained several inorganic ions, and the total content of inorganic ions was about $0.5 \mathrm{~g} / 100 \mathrm{~g}$ honey (Table 3 ). Potassium $\left(\mathrm{K}^{+}\right)$was the main cation, and phosphate $\left(\mathrm{PO}_{4}{ }^{3-}\right)$ was the most abundant anion. Phosphate and sulfate differed significantly between the three groups of honey. The phosphate content was about twofold higher in spruce/Physokermes honey than in Cinara honey.
Table 3 Inorganic anion and cation contents in three groups of honeydew honey (Abies alba/Cinara spec., Picea abies/Cinara spec., and Picea abies/Physokermes spec.)

\begin{tabular}{lrrr}
\hline Ion $[\mathrm{mg} / 100 \mathrm{~g}]$ & Abies alba & \multicolumn{2}{l}{ Picea abies } \\
\cline { 3 - 4 } & Cinara sp. & Cinara sp. & Physokermes $\mathrm{sp}$. \\
\hline Cations & & & \\
Potassium $\left(\mathrm{K}^{+}\right)$ & $219 \pm 51^{\mathrm{a}}$ & $187 \pm 62^{\mathrm{a}}$ & $234 \pm 82^{\mathrm{a}}$ \\
Sodium $\left(\mathrm{Na}^{+}\right)$ & $11 \pm 15^{\mathrm{a}}$ & $10 \pm 13^{\mathrm{a}}$ & $10 \pm 12^{\mathrm{a}}$ \\
Ammonium $\left(\mathrm{NH}_{4}{ }^{+}\right)$ & $5 \pm 5^{\mathrm{a}}$ & $4 \pm 4^{\mathrm{a}}$ & $4 \pm 4^{\mathrm{a}}$ \\
Magnesium $\left(\mathrm{Mg}^{2+}\right)$ & $13 \pm 11^{\mathrm{a}}$ & $14 \pm 8^{\mathrm{a}}$ & $19 \pm 13^{\mathrm{a}}$ \\
Calcium $\left(\mathrm{Ca}^{2+}\right)$ & $14 \pm 24^{\mathrm{a}}$ & $12 \pm 13^{\mathrm{a}}$ & $14 \pm 18^{\mathrm{a}}$ \\
Anions & & & \\
Chloride $\left(\mathrm{Cl}^{-}\right)$ & $32 \pm 14^{\mathrm{a}}$ & $36 \pm 15^{\mathrm{a}}$ & $40 \pm 34^{\mathrm{a}}$ \\
Phosphate $\left(\mathrm{PO}_{4}{ }^{3-}\right)$ & $\mathbf{1 0 4} \pm \mathbf{4 4 ^ { \mathrm { a } }}$ & $\mathbf{1 0 4} \pm \mathbf{3 1}$ & $\mathbf{2 1 2} \pm \mathbf{4 2 ^ { \mathbf { b } }}$ \\
Sulfate $\left(\mathrm{SO}_{4}{ }^{2-}\right)$ & $\mathbf{2 5} \pm \mathbf{8}^{\mathbf{a}, \mathbf{b}}$ & $\mathbf{2 0} \pm \mathbf{6}^{\mathbf{a}}$ & $\mathbf{3 1} \pm \mathbf{1 6}^{\mathbf{b}}$ \\
Nitrate $\left(\mathrm{NO}_{3}{ }^{-}\right)$ & $2 \pm 2^{\mathrm{a}}$ & $1 \pm 2^{\mathrm{a}}$ & $1 \pm 3^{\mathrm{a}}$ \\
\hline
\end{tabular}

All values are means of $n=20$ independent measurements \pm SD

Different letters represent significant differences between the inorganic ion content in the tree groups of honeydew honey. Significantly different values were also marked in bold 


\section{Honey composition in relation to the zoological and botanical origin}

In order to investigate whether the differences in sugar, amino acid, and ion contents could be explained by the zoological and/or botanical origin of the honeydew honey samples, a Powered Partial Least Squares-Discriminant Analysis (PPLS-DA) was performed. All sugar, amino acid, and inorganic ion values were used and autoscaled.

For PPLS-DA, the performance of the model must be assessed before any interpretation of score plots is possible. Therefore, the number of misclassifications (or error rate), i.e., the number of samples that do not belong to the group predicted by the model, was calculated. The classification error rate was about 0.259 using cross model validation (outer loop: sevenfold cross validation, inner loop: sixfold cross validation). Then, a permutation test based on the classification error rate was used to determine the statistical significance of the differences between groups. Because the $p$ value was 0.001 , the interpretation of the score plots can follow (Fig. 1). It was possible to visually separate three groups of honey (fir/Cinara, spruce/ Cinara, and spruce/Physokermes; Fig. 1a), with erlose, undefined sugar 6 , sulfate, and phosphate being responsible for the separation of spruce/Physokermes honey samples (Fig. 1b). Additionally, raffinose and isomaltose were the differentiating variables for the separation of fir/Cinara honey from the other two, and tyrosine, arginine, lysine, isoleucine, and phenylalanine caused the separation of spruce/Cinara from other honeys (Fig. 1b). Lastly, pairwise comparisons showed that within the zoological origins, differs significantly from the other (Table 4).

An additional cross model validation was carried out for the same PPLS-DE according to the botanical origin, fir versus spruce. The classification error rate (CER) was 0.14583 and $p$ value $=0.001 * *$ for 999 permutations. This indicates that fir and spruce honey can be separated
Table $4 p$ values of pairwise comparisons for each pair of zoological origin

\begin{tabular}{lll}
\hline & Fir/Cinara & Spruce/Cinara \\
\hline Spruce/Cinara & 0.001 & - \\
Spruce/Physokermes & 0.001 & 0.001 \\
\hline
\end{tabular}

according to the sugar, amino acid, and inorganic ion content.

\section{Discussion}

Honeydew honey belongs to the main unifloral honey types produced in European countries and, because of its strong malty-aromatic taste, it is very popular [36]. In Germany, fir and spruce honey are the most common honeydew honeys [6], but until now it is hardly possible to distinguish between both types of honeydew honey [8]. Furthermore, honeydew honey compared with floral honey can not only have different botanical origins but also different zoological origins (honeydew producer). Therefore, we focused on three groups of honeydew honey (fir/Cinara, spruce/Cinara, and spruce/Physokermes) and analyzed the sugar, amino acid, and inorganic ion contents in order to examine whether these compounds are useful to distinguish between the different types of honeydew honey.

\section{Differences in the sugar composition}

Fructose and glucose make up about $60 \%$ (w/w) of fir and spruce honey and with that they are the dominant compounds (Table 1). This content is similar to values of other fir honeys from France (measured with HPAEC-PAD), Spain (measured with GC-MS), or Germany (measured by ${ }^{1} \mathrm{H}-\mathrm{NMR}$ ), but it is lower than that of Greek pine and
Fig. 1 Powered Partial LeastSquares-Discriminant Analysis (PPLS-DA). a score plot of the sugar, amino acid, and inorganic ion content observed in three groups of honeydew honey (Fir/Cinara, Spruce/Cinara, Spruce/Physokermes). b Loading plot of sugar, amino acid, and inorganic ion content. CER (classification error rate $)=0.259$. $p$ value $=0.001$, number of permutations $=999$
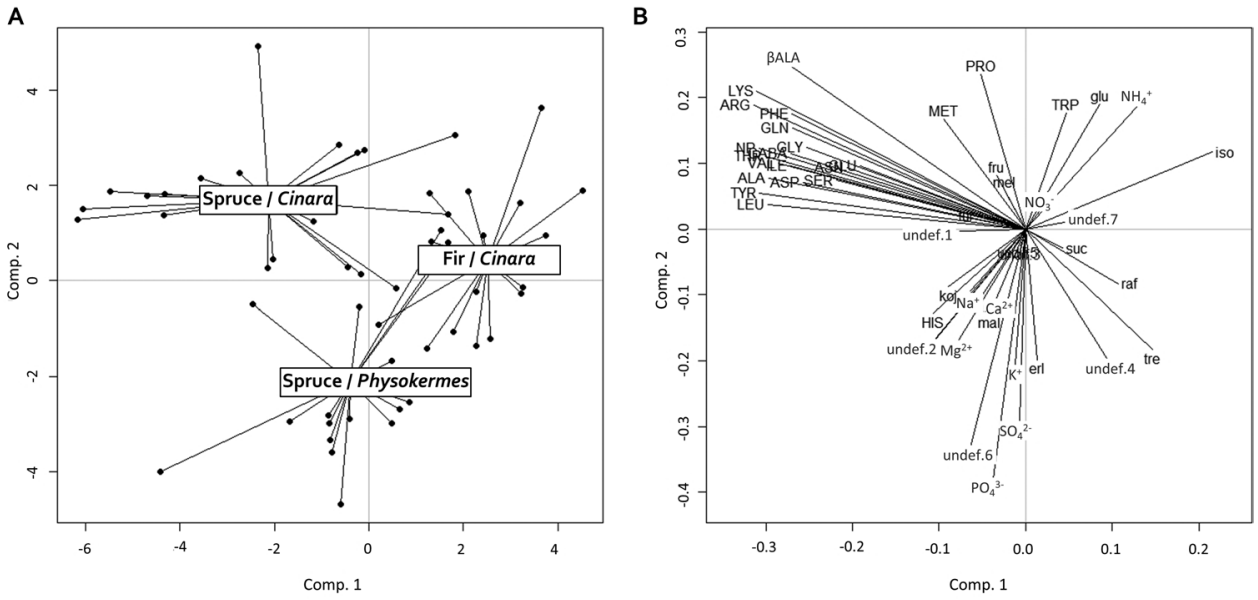
fir honeys (measured ${ }^{1} \mathrm{H}-\mathrm{NMR}$ ) [19, 37-39]. The monosaccharides in honeydew honey can stem from different sources; one part can stem directly from the monosaccharides in the honeydew collected by the bees [5]. The bees themselves can also contribute to the monosaccharides in honeydew honey by cleaving the honeydew's di- or oligosaccharides, probably by the activity of $\alpha$-glucosidases [40]. The trehalose content in the honeydew honey of fir and spruce is about $2 \%(\mathrm{w} / \mathrm{w})$, which is higher than that of several flower honeys $[8,37]$. Trehalose was also found in the honeydew of hemipteran species feeding on fir or spruce [5]. In insects, trehalose serves as a haemolymphsugar and it is the major carbohydrate energy source used by insects to facilitate flight [41].

Fir and spruce honeys contained up to $10 \%$ (w/w) of oligosaccharides, mainly melezitose and erlose (Table 1 ). In general, honeydew honey contains more di- and oligosaccharides than flower honey [8] and the trisaccharide melezitose was reported to be a marker for honeydew honey [42]. There does not seem to be evidence of melezitose formation in honey bees, but the sugar was found in the honeydew of different hemipteran species [4, 5]. Erlose was also found in the honeydew of different hemipteran species [5] and a smaller proportion of erlose could also be produced by the action of honey bee invertase on sucrose [9]. As the phloem sap of most plant species, including fir or spruce, contains only sucrose [5], melezitose and erlose must be produced by the phloem feeding insects or honey bees and not by the plants.

The concentrations of five di- and oligosaccharides differed significantly between the three groups of honeydew honey (Table 1). The content of erlose, undef4, and undef6 was about twofold-threefold higher in spruce/Physokermes honey than in spruce/- or fir/Cinara honey. Von der Ohe and von der Ohe [43] reported the detection of particular oligosaccharides (named L1 and L2) in Physokermes honey; the structures of these sugars, however, have not yet been resolved. It can be assumed that undef 4 and undef 6 as well as L1 and L2 are the same oligosaccharides, further analyses are necessary for a final clarification. The sugar composition in the honeydew honey samples also allow for the distinction between fir and spruce honey (Table 1). The content of isomaltose and raffinose was higher in fir/Cinara honey than in spruce/Cinara or spruce/Physokermes honey. Similar contents of raffinose were also found in French and Greek fir honeys [19, 37]. Moreover, the raffinose content was higher in Greek fir honeys compared to pine honeys [19]. Because the sugar composition of honeys is also influenced by the geographic origin and the high biological variability within different honey samples [19], a number of studies is needed to characterize honeydew honeys of different botanical origins only on the basis of their carbohydrate compositions [8].

\section{Differences in the amino acid composition}

Although numerous amino acids were found in fir and spruce honeys, the total amino acid content was less than $0.1 \%(\mathrm{w} / \mathrm{w})$. The amino acids in honeydew honey can stem from different sources; for example, the honeydew alone already contains small amounts of amino acids [2, 5]. However, the sugar-to-amino acid ratio is higher in honeydew than in nectar, which means that a honeydew diet for honey bees is less rich in nitrogen than a nectar diet $[44,45]$. The bees themselves can also contribute to the amino acids in honey, particularly to the amount of proline, and ripe honey should contain at least $180 \mathrm{mg}$ proline $\mathrm{kg}^{-1}$ honey [46].

The contents of several amino acids (proline, glutamate, glutamine, aspartate, asparagine, threonine, alanine, valine, isoleucine, phenylalanine, tyrosine, arginine, lysine, B-alanine) were significantly higher in spruce/Cinara honey than in fir/Cinara or in spruce/Physokermes honey. Proline and phenylalanine contents in honey have already been shown in previous studies to be suitable to characterize the botanical origin of flower honeys or to differentiate between flower honeys and honeydew honey [13]. It was possible to identify samples of lavender honey on the basis of high phenylalanine contents [13]. However, similarly high contents of phenylalanine were also detected in honeys of other Lamiaceae, like Rosmarinus or Thymus [47]. One reason for this could be the high content of phenylalanine in the nectar of some Lamiaceae species [48], probably because phenylalanine has a phagostimulatory effect on potential pollinators, like honey bees [49]. The proline content in honey also depends on the botanical origin [13] but the variation of the proline content in different unifloral honeys is quite high and it seems not to be possible to classify unifloral honey on this basis $[13,50]$. The ripeness of honey also has an influence on the proline content [46]. A high degree of variability in the phenylalanine and proline content was shown for Greek fir honeys from different geographical regions [19]. Moreover, the amino acid content in honey decreases with storage time and the decrease-rate is not identical for the individual amino acids [51]. Therefore, the differentiation between different honeydew honeys solely on the basis of the amino acid composition appears to be insufficient [8].

\section{Differences in the inorganic ion composition}

Honeydew honey contains more inorganic ions than flower honey [15] and this can be a reason for the higher electrical conductivity of honeydew honey [52]. Potassium is the main inorganic ion in all honey samples (Table 3 ) and it is also the dominant ion in the honeydew of hemipteran species feeding on fir or spruce as well as in the phloem exudates of these tree species [5]. Yet, not only potassium, but the complete inorganic ion composition (with the exception of phosphate) 
in honey roughly reflects the composition in honeydew or phloem exudates of fir and spruce. The proportion of phosphate was higher in all honey samples than it is in honeydew or phloem exudates of fir and spruce (Table 3) [5]. As inorganic ions are taken up from the soil by the plant's roots, their content and composition in honeys are indirectly dependent on the soil composition and the geographic area $[15,18,52]$. However, the honeydew honeys used in this study were all from the same state (Baden-Württemberg) in Germany to minimize variation due to different geographic areas. Differences in the inorganic ion contents in honeys are also used to identify their botanical origin, but the major differences were found between flower and honeydew honey $[15,18,52,53]$.

As for the inorganic ions, only sulfate and phosphate differed significantly between the three groups of honeydew honey (Table 3). The content of both ions is about 1.5-twofold higher in spruce/Physokermes honey than in spruce/Cinara or fir/Cinara honey. This corresponds to the results on the ion composition in honeydew, as the proportion of phosphate was particularly high in the honeydew of Physokermes species located on spruce compared to Cinara species located on spruce or fir [5]. Therefore, the inorganic ion composition seems to be more useful for the determination of the honeys' zoological origin than its botanical origin.

\section{Suitability of the sugar, amino acid, and inorganic ion composition for the distinction between different honeydew honeys}

A significant variation of the sugar, amino acid, and ion contents for the three groups of honey (fir/Cinara, spruce/Cinara, spruce/Physokermes) was visible in the PPLS-DA (Fig. 1). Moreover, permutation tests based on the cross-validation model were performed and $p$ values $<0.05$ support the visual separation of the honey groups. In addition, pairwise comparisons showed that within the zoological origins, each differs significantly from the other (Table 4). Fir honey can be separated from spruce honey mainly due to its higher contents of raffinose and isomaltose. Spruce/Physokermes honey can be separated from spruce/Cinara or fir/Cinara honey mainly due to its higher contents of sulfate, phosphate, erlose, and two undefined oligosaccharides (undef4 and undef6), and spruce/Cinara honey can be separated from fir/Cinara or spruce/Physokermes honey mainly due to its higher contents of several amino acids.

In sum, the three groups of honeydew honey could be separated by their sugar, amino acid, and ion composition and not by single chemical markers. Moreover, it should be noted that further factors may influence the honey's chemical composition, such as geographical origin, collection season, weather conditions, conditions of honey harvest and storage $[8,54]$.

\section{Conclusion}

Honeydew honey belongs to the main unifloral honey types produced in European countries and, because of its strong malty-aromatic taste, it is very popular. Honeydew honey can stem from different botanical as well as zoological origins, but so far it is not possible to clearly distinguish the different types of honeys. Therefore, a metabolomics approach associated with multivariate analysis was applied to authenticate the most common honeydew honeys in Germany (fir/ Cinara., spruce/Cinara, and spruce/Physokermes). In sum, the three groups of honeydew honey could be separated by their sugar, amino acid, and ion composition. Therefore, the metabolite compositions provide useful information about the botanical and zoological origin of honeydew honeys. This contributes to a more accurate labeling of honeydew honeys.

Acknowledgements The authors like to thank Rosi Ritter for critical reading of the manuscript and the reviewers for the helpful comments.

Funding Open Access funding enabled and organized by Projekt DEAL. The project is supported by funds of the Federal Ministry of Food and Agriculture (BMEL) based on a decision of the Parliament of the Federal Republic of Germany via the Federal Office for Agriculture and Food (BLE) under the innovation support program (Grant no. 2816500114 ) to G.L. and A.S.

\section{Compliance with ethical standards}

Conflict of interest The authors declare that they have no conflict of interest.

Compliance with ethics requirements The article does not contain any studies with human participants or animal subjects.

Open Access This article is licensed under a Creative Commons Attribution 4.0 International License, which permits use, sharing, adaptation, distribution and reproduction in any medium or format, as long as you give appropriate credit to the original author(s) and the source, provide a link to the Creative Commons licence, and indicate if changes were made. The images or other third party material in this article are included in the article's Creative Commons licence, unless indicated otherwise in a credit line to the material. If material is not included in the article's Creative Commons licence and your intended use is not permitted by statutory regulation or exceeds the permitted use, you will need to obtain permission directly from the copyright holder. To view a copy of this licence, visit http://creativecommons.org/licenses/by/4.0/.

\section{References}

1. Directive 2014/63/EU of the European Parliament and of the Council amending Council Directive 2001/110/EC relating to honey (2014) Off J Eur Communities 164:1-5 
2. Douglas AE (2006) Phloem-sap feeding by animals: problems and solutions. J Exp Bot 57:747-754

3. Hendrix DL, Wie Y, Legget JE (1992) Homopteran honeydew is determined by both the insect and the plant species. Comp Biochem Physiol 101:23-27

4. Fischer MK, Shingleton AW (2001) Host plant and ants influence the honeydew sugar composition of aphids. Funct Ecol 15:544-550

5. Shaaban B, Seeburger V, Schroeder A, Lohaus G (2020) Sugar, amino acid and inorganic ion profiling of the honeydew from different hemipteran species feeding on Abies alba and Picea abies. PLoS ONE 15(1):e0228171

6. Kunkel H, Kloft WJ (1985) Die Honigtau-Erzeuger des Waldes. In: Kloft WJ, Kunkel H (eds) Waldtracht und Waldhonig in der Imkerei. Ehrenwirth, Munich, pp 48-265

7. Vasić V, Durdića S, Tostia T, Radoičićb A, Lušićc D, MilojkovićOpsenicaa D, Tešića Z, Trifkovića J (2020) Two aspects of honeydew honey authenticity: Application of advance analytical methods and chemometrics. Food Chem 305:125457

8. Pita-Calvo C, Vázquez M (2018) Honeydew honeys: a review on the characterization and authentication of floral and geographical origins. J Agric Food Chem 66:2523-2537

9. Doner LW (1977) The sugars of honey-a review. J Sci Food Agric 28(5):443-456

10. Ruoff K, Luginbühl W, Kilchenmann V, Bosset JO, von der Ohe K, von der Ohe W, Amadò R (2007) Authentication of the botanical origin of honey using profiles of classical measurands and discriminant analysis. Apidologie 38:438-452

11. Cordella CBY, Militão JSLT, Clément MC, Cabrol-Bass D (2003) Honey characterization and adulteration detection by pattern recognition applied on HPAEC-PAD profiles. 1. Honey floral species characterization. J Agric Food Chem 51:3224-3324

12. Spiteri M, Jamin E, Thomas F, Rebours A, Lees M, Rogers KM, Rutledge DN (2015) Fast and global authenticity screening of honey using ${ }^{1} \mathrm{H}-\mathrm{NMR}$ profiling. Food Chem 189:60-66

13. Cotte JF, Casabianca H, Giroud B, Albert M, Lheritier J, GrenierLoustalot M (2004) Characterization of honey amino acid profiles using high-pressure liquid chromatography to control authenticity. Anal Bioanal Chem 378:1342-1350

14. Iglesias MT, de Lorenzo C, Polo MC, Martín-Álvarez PJ, Pueyo E (2004) Usefulness of amino acid composition to discriminate between honeydew and floral honeys. Application to honeys from a small geographic area. J Agric Food Chem 52:84-89

15. Fermo P, Beretta G, Facino RM, Gelmini F, Piazzalunga A (2013) Ionic profile of honey as a potential indicator of botanical origin and global environmental pollution. Environ Pollut 178:173-181

16. Jovetić M, Trifković J, Stanković D, Manojlović D, MilojkovićOpsenica D (2017) Mineral content as a tool for the assessment of honey authenticity. J AOAC Intern 100:862-870

17. Bogdanov SM, Luginbühl W, Gllmann P (2007) Minerals in honey: environmental, geographical and botanical aspects. J Apic Res Bee World 46:269-275

18. Karabagias IK, Louppis AP, Badeka A, Papastephanou C, Kontominas MG (2019) Nutritional aspects and botanical origin recognition of Mediterranean honeys based on the "mineral imprint" with the application of supervised and non-supervised statistical techniques. Eur Food Res Technol 245:1939-1949

19. Karabagias IK, Vlasiou M, Kontakosi S, Drouza C, Kontominas MG, Keramidas AD (2018) Geographical discrimination of pine and fir honeys using multivariate analyses of major and minor honey components identified by $1 \mathrm{H}$ NMR and HPLC along with physicochemical data. Eur Food Res Technol 244:1249-1259

20. Vasić V, Gašić U, Stanković D, Lušić D, Lušić VD, Opsenica MD, Trifković J (2019) Towards better quality criteria of European honeydew honey: phenolic profile and antioxidant capacity. Food Chem 247:629-641
21. Castro-Vázquez L, Diaz-Maroto MC, Pérez-Coello MS (2006) Volatile composition and contribution to the aroma of Spanish honeydew honeys. Identification of a mew chemical marker. J Agric Food Chem 54:4809-4813

22. Sanz ML, Gonzalez M, De Lorenzo C, Sanz J, Martínez-Castro I (2005) A contribution to the differentiation between nectar honey and honeydew honey. Food Chem 91(2):313-317

23. Tananaki C, Thrasyvoulou A, Giraudel JL, Montury M (2007) Determination of volatile characteristics of Greek and Turkish pine honey samples and their classification by using Kohonen self organising maps. Food Chem 101(4):1687-1693

24. Simova S, Atanassov A, Shishiniova M, Bankova VA (2012) rapid differentiation between oak honeydew honey and nectar and other honeydew honeys by NMR spectroscopy. Food Chem 134(3):1706-1710

25. Kuś PM, Jerković I, Marijanović Z, Tuberoso CIG (2017) Screening of polish fir honeydew honey using GC/MS, HPLCDAD, and physical-chemical parameters: benzene derivatives and terpenes as chemical markers. Chem Biodivers 14(9):e1700179

26. Spilioti E, Jaakkola M, Tolonen M, Lipponen M, Virtanen V, Chinou I, Kassi E, Karabournioti S, Moutsatsou P (2014) Phenolic acid composition, antiatherogenic and anticancer potential of honeys derived from various regions in Greece. PLoS ONE 9(4):e94860

27. Bertoncelj J, Polak T, Kropf U, Korošec M, Golob T (2011) LC-DAD-ESI/MS analysis of flavonoids and abscisic acid with chemometric approach for the classification of Slovenian honey. Food Chem 127(1):296-302

28. Göttlinger T, Schwerdtfeger M, Tiedge K, Lohaus G (2019) What do nectarivorous bats like? Nectar composition in Bromeliaceae with special emphasis on bat-pollinated species. Front Plant Sci 10:205

29. West SG, Finch JF, Curran PJ (1995) Structural equation models with nonnormal variables: problems and remedies. In: Hoyle RH (ed) Structural equation modeling: concepts, issues and applications. Newbery Park, CA Sage, pp 56-75

30. Brereton RG, Lloyd GR (2014) Partial least squares discriminant analysis: taking the magic away. J Chemom 28:213-225

31. Kjeldahl K, Bro R (2010) Some common misunderstandings in chemometrics. J Chemom 24:558-564

32. Westerhuis JA, Hoefsloot HCJ, Smit S, Vis DJ, Smilde AK, van Velzen EJJ, van Duijnhoven JPM, van Dorsten FA (2008) Assessment of PLSDA cross validation. Metabolomics 4:81-89

33. Worley B, Powers R (2013) Multivariate analysis in metabolomics . Curr Metab 1:92-107

34. Mevik B-H, Wehrens R, Liland KH, Hiemstra P (2019). pls: Partial least squares and principal component regression. $\mathrm{R}$ package version 2.7-3. https://CRAN.R-project.org/package=pls. Accessed 27 Aug 2020

35. Hervé M (2019) RAVideMemoire: testing and plotting procedures for biostatistics. R package version 0.9-73. https://CRAN.R-proje ct.org/package $=$ RVAideMemoire. Accessed 27 Aug 2020

36. Persano Oddo L, Piro R (2004) Main European unifloral honeys: descriptive sheets. Apidologie 35:S38-S81

37. Cotte JF, Casabianca H, Chardon S, Lheritier J, Grenier-Loustalot MF (2004) Chromatographic analysis of sugars applied to the characterization of monofloral honey. Anal Bioanal Chem 380:698-705

38. De la Fuente E, Sanz ML, Martínez-Castro I, Sanz J, Ruiz-Matute AI (2007) Volatile and carbohydrate composition of rare unifloral honeys from Spain. Food Chem 105(1):84-93

39. Ohmenhaeuser M, Monakhova YB, Kuballa T, Lachenmeier DW (2013) Qualitative and quantitative control of honeys using NMR spectroscopy and chemometrics. Hindawi Publishing Corporation ISRN Anal Chem 2013:9. https://doi.org/10.1155/2013/825318 
40. Kubota M, Tsuji M, Nishimoto M, Wongchawalit J, Okuyama M, Mori H (2004) Localization of $\alpha$ glucosidases I, II, and III in organs of European honeybees, Apis mellifera L., and the origin of $\alpha$-glucosidase in honey. Biosci Biotechnol Biochem 68:2346-2352

41. Thompson SN (2003) Trehalose-the insect 'blood' sugar. Adv Insect Physiol 31:205-285

42. Maurizio A (1962) From the raw material to the finished product: honey. Bee World 43(3):66-81

43. Von der Ohe W, von der Ohe K (1996) Charakterisierung von Honigtauhonig anhand spezifischer Saccharide. Apidologie 27(4):270-272

44. Lohaus G, Schwerdtfeger M (2014) Comparision of sugars, iridoid glycosides and amino acids in nectar and phloem sap of Maurandya barclayana, Lophospermum erubescens, and Brassica napus. PLoS ONE 9(1):e87689

45. Tiedge K, Lohaus G (2017) Nectar sugars and amino acids in dayand night-flowering Nicotiana species are more strongly shaped by pollinators' preferences than organic acids and inorganic ions. PLoS ONE 12(5): 0176865

46. Von der Ohe W, Dustmann JH, von der Ohe K (1991) Prolin als Kriterium der Reife des Honigs. Dtsch Lebensm Rundsch $87: 383-386$

47. Conte LS, Miorini M, Giomo A, Bertacco G, Zironi R (1998) Evaluation of some fixed components for unifloral honey characterization. J Agric Food Chem 46:1844-1849

48. Petanidou T, Van Laere A, Ellis WN, Smets E (2006) What shapes amino acid and sugar composition in Mediterranean floral nectars? Oikos 115:155-169
49. Inouye DW, Waller GD (1984) Responses of honeybees (Apis mellifera) to amino acid solutions mimicking floral nectars. Ecology 65:618-625

50. Sanchez MD, Huidobro JF, Mato I, Muniategui S, Sancho MT (2001) Correlation between proline content of honeys and botanical origin. Dtsch Lebensm Rundsch 97:171-175

51. Iglesias MT, Martín-Álvarez PJ, Polo MC, de Lorenzo C, González M, Pueyo E (2006) Changes in the free amino acid contents of honeys during storage at ambient temperature. J Agric Food Chem 54:9099-9104

52. Bogdanov S, Haldimann M, Luginbuhl W, Gallmann P (2007) Minerals in honey: environmental, geographical and botanical aspects. J Apic Res 46:269-275

53. Fernández-Torres R, Pérez-Bernal JL, Bello-López MA, Callejón-Mochón M, Jiménez-Sánchez JC, Guiraúm-Pérez A (2005) Mineral content and botanical origin of Spanish honeys. Talanta 65:686-691

54. Soares S, Amaral JS, Oliveira MBPP, Mafra I (2017) A comprehensive review on the main honey authentication issues: production and origin. Compr Rev Food Sci Saf 16:1072-1100

Publisher's Note Springer Nature remains neutral with regard to jurisdictional claims in published maps and institutional affiliations. 